\title{
Metastatic Malignant Genitourinary System Neoplasm
}

National Cancer Institute

\section{Source}

National Cancer Institute. Metastatic Malignant Genitourinary System Neoplasm. NCI

Thesaurus. Code C157774.

A malignant neoplasm that arises from the genitourinary system and has metastasized to other anatomic sites. 